\title{
Radiotherapy of Grade III Gliomas: Identification of Clinical Prognostic Factors for Local Tumor Control and Survival
}

\author{
DIRK RADES ${ }^{1}$, JASPAR WITTELER $^{1}$ and STEVEN E. SCHILD ${ }^{2}$ \\ ${ }^{1}$ Department of Radiation Oncology, University of Lübeck, Lübeck, Germany; \\ ${ }^{2}$ Department of Radiation Oncology, Mayo Clinic, Scottsdale, AZ, U.S.A.
}

\begin{abstract}
Background/Aim: The prognoses of patients with grade III gliomas require improvement, which may be achieved with personalized care. We aimed to identify prognostic factors to facilitate the process of treatment personalization. Patients and Methods: Eight factors were analyzed for local tumor control and survival in 44 patients irradiated for grade III glioma. These factors included location and size of glioma, number of glioma sites, performance status, gender, age, neurosurgical intervention and chemotherapy. Results: In the Cox regression analyses, frontal location (risk ratio=4.41, $p=0.048$ ) and unifocal glioma (risk ratio=4.65, $p=0.034$ ) were associated with improved local control, and unifocal glioma with improved survival (risk ratio=6.12, $p=0.033$ ). In addition, trends for better survival were observed for frontal location $(p=0.093)$, age $\leq 49$ years $(p=0.070)$, upfront resection $(p=0.099)$ and chemotherapy $(p=0.066)$ on univariate analyses. Conclusion: Independent predictors of local tumor control and survival were identified that can be helpful for personalizing treatment and designing clinical trials.
\end{abstract}

The World Health Organization (WHO) classification of gliomas includes four grades (I-IV), and grade III gliomas are considered high-grade tumors $(1,2)$. Grade III gliomas are rare and account for about $3 \%$ of primary brain tumors and tumors of the central nervous system (3-5). Patients with grade III gliomas often have comparably poor prognoses, and the tumors can also negatively impact patients' quality of life

This article is freely accessible online.

Correspondence to: Prof. Dirk Rades, MD, Department of Radiation Oncology, University of Lübeck, Lübeck, Ratzeburger Allee 160, 23562 Lübeck, Germany. Tel: +49 45150045401, Fax: +49 45150045404, e-mail: dirk.rades@uksh.de

Key Words: Grade III glioma, neurosurgical intervention, irradiation, local tumor control, survival.
(5). When compared to low-grade gliomas (grade I or II) and glioblastomas (grade IV), fewer studies have focused on diagnosis, treatment and prognosis of grade III gliomas (5). Moreover, most studies investigating high-grade gliomas combine grade III and IV tumors, although the progoses are quite different, and are dominated by the significantly more common grade-IV tumors $(5,6)$. Therefore, the present study was conducted including only patients with grade III gliomas. Its major goal is the identification of independent prognostic factors for local tumor control and survival that can lead to better personalization of individual treatment programs and likely to an improvement of the patients' prognoses.

\section{Patients and Methods}

The data of 44 patients receiving radiotherapy for grade III glioma were retrospectively analyzed for local tumor control and survival. The study had received its approval from the local Ethics Committee at the University of Lübeck (reference $=15-355 \mathrm{~A}$ ). Radiotherapy was performed after biopsy only $(\mathrm{n}=13,30 \%)$ or after resection $(n=31,70 \%)$. Gross tumor resection was achieved in 7 patients, and macroscopically incomplete resection in 22 patients; the extent of resection remained unclear in 2 patients. The median total dose of radiotherapy following neurosurgical intervention was 59.4 Gy (54.0-60.0 Gy), and the median dose per fraction $1.8 \mathrm{~Gy}$ (1.8-2.0 Gy). Thirty-three patients (75\%) received additional chemotherapy, most frequently with temozolomide (TMZ) alone (23 patients). Moreover, three patients received PC-chemotherapy including procarbazine and lomustine (CCNU) alone, six patients sequential administration of both TMZ and PC, and one patient nimustine (ACNU) alone.

Eight factors were analyzed for a potential prognostic impact with respect to local tumor control and survival, including main location of the glioma (frontal vs. other locations), number of glioma sites (unifocal vs. multifocal), cumulative maximum diameter of the glioma [ $<35 v s . \geq 35 \mathrm{~mm}$, according to Fang et al. (5)], Karnofsky performance score (KPS) ( $\leq 80 v s .>80 \%)$, gender, age at start of radiotherapy [ $\leq 49 v s .>49$ years, according to Curran et al. (7)], upfront neurosurgical intervention (biopsy vs. resection), and chemotherapy in addition to radiotherapy (no $v s$. yes). Frontal location $(n=22)$ included frontal location only $(n=14)$, frontotemporal location $(n=5)$, fronto-parietal location $(n=2)$ and frontal 
plus paraventricular location $(n=1)$. The distributions of the eight factors are shown in Table I.

Time to local tumor progression and time to death were referenced from the last day of irradiation. Univariate analyses for both endpoints were performed with the Kaplan-Meier method plus log-rank test. $p$-Values $<0.10$ indicated a trend, and $p$-values $<0.05$ demonstrated significance. The significant factors were subsequently included in a multivariate Cox regression analysis.

\section{Results}

Data for local tumor control were available for 35 patients. In these patients, the median time to local failure was 44 months, and local control rates at 1,2 and 3 years were $73 \%$, $68 \%$ and $57 \%$, respectively. On univariate analysis of local tumor control, frontal location $(p=0.020)$ and unifocal glioma $(p=0.002)$ were significantly associated with improved outcomes (Table II). In the Cox regression analysis, both main location of the glioma (risk ratio $=4.41$, 95\% CI $=1.01-31.10, p=0.048)$ and number of glioma sites (risk ratio $=4.65,95 \% \mathrm{CI}=1.13-17.98, p=0.034$ ) remained significant.

In the entire cohort of 44 patients, median survival following radiotherapy was 132 months, and survival rates at 1, 2 and 3 years were 93\%,83\% and 68\%, respectively. On univariate analysis of survival, unifocal glioma $(p=0.009)$ were significantly associated with improved outcomes (Table III). In addition, trends were observed for frontal location $(p=0.093)$, age $\leq 49$ years $(p=0.070)$, resection prior to irradiation $(p=0.099)$ and additional chemotherapy $(p=0.066)$. In the Cox regression analysis, number of glioma sites (risk ratio $=6.12,95 \%$ confidence interval $=1.17-28.68, p=0.033$ ) maintained significance.

\section{Discussion}

In total, gliomas account for approximately $30 \%$ of primary brain tumors (8). Of all gliomas, only about $10 \%$ are grade III tumors (3-5). These patients were reported to have poor prognoses. Because of the rarity of grade III gliomas, very few studies have focused specifically on this subgroup of gliomas. The outcomes of patients with malignant diseases may be improved with personalized treatment programs, ideally, considering the individual prognostic factors for each patient. Survival is an important outcome that should be considered when selecting an optimal personalized treatment. In general, patients with poor estimated survival should receive short and little burdensome treatments, whereas tumor control and late sequelae require higher attention when aiming to treat longterm survivors. These strategies were particularly described for patients with metastatic cancer, but can also be important for patients with grade III gliomas (9-12).

This study was conducted to identify prognostic factors for survival and local tumor control in patients receiving
Table I. Factors evaluated for local control and survival.

\begin{tabular}{lc}
\hline Factor & Number of patients (\%) \\
\hline Main location of glioma & \\
Frontal & $22(50)$ \\
Other & $22(50)$ \\
Number of glioma sites & \\
Unifocal & $35(80)$ \\
Mutifocal & $7(16)$ \\
Unknown & $2(5)$ \\
Cumulative maximum diameter & \\
$<35$ mm & $12(27)$ \\
$\geq 35$ mm & $18(41)$ \\
Unknown & $14(32)$ \\
Karnofsky performance score & \\
$\leq 80 \%$ & $20(45)$ \\
$>80 \%$ & $21(48)$ \\
Unknown & $3(7)$ \\
Gender & \\
Female & $22(50)$ \\
Male & $22(50)$ \\
Age at start of radiotherapy & \\
$\leq 49$ Years & $25(57)$ \\
$>49$ Years & $19(43)$ \\
Upfront neurosurgical intervention & \\
Biopsy & $13(30)$ \\
Resection & $31(70)$ \\
Additional chemotherapy & \\
No & $11(25)$ \\
Yes & $33(75)$ \\
\hline & \\
\hline &
\end{tabular}

radiotherapy after neurosurgical intervention for grade III glioma. In addition to survival, local tumor control is important, since local progression is often the life-limiting factor in glioma patients whose tumors do not metastasize. In the present study, frontal location and unifocal glioma showed significant associations with better local tumor control in the multivariate analysis. Improved survival was independently associated with unifocal glioma; trends were observed on univariate analyses for frontal location, age $\leq 49$ years, upfront resection, and addition of chemotherapy.

Some of these factors were previously identified as associated with outcomes after treatment for grade III glioma, which demonstrates consistency regarding our present findings. However, when interpreting these findings, one should consider the limitations of this study including its retrospective nature and small sample size. In 2009, Park et al. reported a retrospective series of 133 patients with grade III gliomas, who received radiotherapy (mean dose $=59.4 \mathrm{~Gy}$ ) with $(50 \%)$ or without $(50 \%)$ PCV-chemotherapy (procarbazine, CCNU, vincristine) (13). In the multivariate analysis, age $<50$ years $(p=0.002)$, Eastern Cooperative Oncology Group performance score 0 -1 representing a better performance status $(p=0.003)$, and complete tumor resection 
Table II. Univariate analyses of local tumor control at 1,2 and 3 years after radiotherapy $(n=35)$.

\begin{tabular}{|c|c|c|c|c|}
\hline Factor & $\begin{array}{c}1 \text { Year } \\
(\%)\end{array}$ & $\begin{array}{c}2 \text { Years } \\
(\%)\end{array}$ & $\begin{array}{c}3 \text { Years } \\
(\%)\end{array}$ & $p$-Value \\
\hline \multicolumn{5}{|c|}{ Main location of glioma } \\
\hline Frontal $(\mathrm{n}=17)$ & 87 & 87 & 87 & \multirow[t]{2}{*}{0.020} \\
\hline Other $(\mathrm{n}=18)$ & 60 & 50 & 0 & \\
\hline \multicolumn{5}{|c|}{ Number of glioma sites } \\
\hline Unifocal (n=27) & 80 & 80 & 67 & \multirow[t]{2}{*}{0.002} \\
\hline Mutifocal (n=7) & 40 & 0 & 0 & \\
\hline \multicolumn{5}{|c|}{ Cumulative maximum diameter } \\
\hline$<35 \mathrm{~mm}(\mathrm{n}=10)$ & 64 & 64 & 64 & \multirow[t]{2}{*}{0.58} \\
\hline$\geq 35 \mathrm{~mm}(\mathrm{n}=14)$ & 75 & 75 & 56 & \\
\hline \multicolumn{5}{|c|}{ Karnofsky performance score } \\
\hline$\leq 80 \%(\mathrm{n}=15)$ & 64 & 43 & 43 & \multirow[t]{2}{*}{0.22} \\
\hline$>80 \%(\mathrm{n}=17)$ & 75 & 75 & 60 & \\
\hline \multicolumn{5}{|l|}{ Gender } \\
\hline Female $(n=17)$ & 62 & 62 & 41 & \multirow[t]{2}{*}{0.21} \\
\hline Male $(n=18)$ & 86 & 73 & 73 & \\
\hline \multicolumn{5}{|c|}{ Age at start of radiotherapy } \\
\hline$\leq 49$ Years $(\mathrm{n}=18)$ & 68 & 69 & 57 & \multirow[t]{2}{*}{0.93} \\
\hline$>49$ Years $(n=17)$ & 79 & n.a. & n.a. & \\
\hline \multicolumn{5}{|c|}{ Upfront neurosurgical intervention } \\
\hline Biopsy $(\mathrm{n}=10)$ & 83 & 83 & 83 & \multirow[t]{2}{*}{0.38} \\
\hline Resection $(n=25)$ & 71 & 65 & 52 & \\
\hline \multicolumn{5}{|c|}{ Additional chemotherapy } \\
\hline No $(n=8)$ & 75 & 75 & 75 & \multirow[t]{2}{*}{0.30} \\
\hline Yes $(n=27)$ & 73 & 67 & 54 & \\
\hline
\end{tabular}

n.a.: Not available, bold $p$-values=significant. If the number of patients is less than 35 for a factor, data were not available for all patients.
Table III. Univariate analyses of survival at 1,2 and 3 years after radiotherapy $(n=44)$.

\begin{tabular}{|c|c|c|c|c|}
\hline Factor & $\begin{array}{c}1 \text { Year } \\
(\%)\end{array}$ & $\begin{array}{c}2 \text { Years } \\
(\%)\end{array}$ & $\begin{array}{c}3 \text { Years } \\
(\%)\end{array}$ & $p$-Value \\
\hline \multicolumn{5}{|c|}{ Main location of glioma } \\
\hline Frontal $(n=22)$ & 95 & 84 & 84 & \multirow[t]{2}{*}{0.093} \\
\hline Other $(n=22)$ & 91 & 79 & 43 & \\
\hline \multicolumn{5}{|c|}{ Number of glioma sites } \\
\hline Unifocal (n=35) & 91 & 88 & 76 & \multirow[t]{2}{*}{0.009} \\
\hline Mutifocal (n=7) & 100 & 33 & 0 & \\
\hline \multicolumn{5}{|c|}{ Cumulative maximum diameter } \\
\hline$<35$ mm (n=10) & 100 & 89 & 89 & \multirow[t]{2}{*}{0.87} \\
\hline$\geq 35 \mathrm{~mm}(\mathrm{n}=18)$ & 88 & 88 & 66 & \\
\hline \multicolumn{5}{|c|}{ Karnofsky performance score } \\
\hline$\leq 80 \%(\mathrm{n}=20)$ & 89 & 73 & 50 & \multirow[t]{2}{*}{0.25} \\
\hline$>80 \%(\mathrm{n}=21)$ & 95 & 87 & 79 & \\
\hline \multicolumn{5}{|l|}{ Gender } \\
\hline Female $(\mathrm{n}=22)$ & 95 & 81 & 72 & \multirow[t]{2}{*}{0.64} \\
\hline Male $(n=22)$ & 91 & 85 & 65 & \\
\hline \multicolumn{5}{|c|}{ Age at start of radiotherapy } \\
\hline$\leq 49$ Years $(n=25)$ & 92 & 87 & 75 & \multirow[t]{2}{*}{0.070} \\
\hline$>49$ Years $(n=19)$ & 95 & 76 & 0 & \\
\hline \multicolumn{5}{|c|}{ Upfront neurosurgical intervention } \\
\hline Biopsy $(n=13)$ & 85 & 71 & 47 & \multirow[t]{2}{*}{0.099} \\
\hline Resection $(\mathrm{n}=31)$ & 97 & 87 & 74 & \\
\hline \multicolumn{5}{|c|}{ Additional chemotherapy } \\
\hline No $(n=11)$ & 80 & 80 & 40 & \multirow[t]{2}{*}{0.066} \\
\hline Yes $(n=33)$ & 97 & 84 & 78 & \\
\hline
\end{tabular}

n.a.: Not available, bold $p$-values=significant. If the number of patients is less than 44 for a factor, data were not available for all patients.
( $p=0.014)$ were significantly associated with improved survival. In 2015, a retrospective study of 90 patients treated with radiotherapy or chemo-radiotherapy with TMZ for grade III astrocytoma was presented from Mainz in Germany (14). In the multivariate analysis, age $\leq 49$ years was significantly associated with progression-free survival (local tumor control, $p=0.005)$ and overall survival $(p=0.001)$. A significant impact was also found for complete and partial tumor resection when compared to biopsy (14). On univariate analysis of another retrospective study, which included 122 patients with a grade III glioma, extent of resection $\geq 53 \%(p=0.021)$ and Karnofsky performance score $\geq 80 \% \quad(p=0.002)$ were significantly associated with better survival, and age $<50$ years $(p=0.091)$ showed a trend (15). In that study, $97.5 \%$ of patients received radiotherapy and 95\% chemotherapy (15). In an analysis of data of patients with grade III gliomas extracted from a Surveillance, Epidemiology and End Results (SEER) database, younger age and surgery were significantly associated with better survival (5). Similar to our present study, frontal location was associated with a more favorable prognosis than other locations (5).

In addition to prognostic factors identified in previous studies, the number of glioma sites was an independent prognostic factor for both local tumor control and survival in the present study. To our knowledge, this factor has not yet been evaluated specifically in patients with grade III gliomas. However, in our previous study of grade II-IV gliomas $(n=222)$, where the majority of patients $(73 \%)$ had grade IV tumors, unifocal glioma showed a significantly positive association with survival on univariate analysis $(p<0.001)$ and a trend in the multivariate analysis $(p=0.062)$ (16). Moreover, in another study of 139 patients with grade IV gliomas, multi-lobar glioma was associated with worse survival than uni-lobar glioma $(p<0.001)(17)$. These data support the present finding that unifocal glioma is a significant prognostic factor for treatment outcomes in patients with grade III gliomas.

In summary, independent predictors of local tumor control and survival were identified for patients with grade III gliomas including a new factor, namely number of glioma sites. These prognostic factors that can be helpful for personalizing treatments and designing future clinical trials.

\section{Conflict of Interest}

The Authors report no conflicts of interest regarding this study. 


\section{Authors' Contributions}

D.R., J.W. and S.E.S. participated in the design of the study. J.W. collected the data that were analyzed by all Authors. D.R. and S.E.S. drafted the article, which was reviewed and finally approved by all Authors.

\section{References}

1 Louis DN, Ohgaki H, Wiestler OD, Cavenee WK, Burger PC, Jouvet A, Scheithauer BW and Kleihues P: The 2007 WHO classification of tumours of the central nervous system. Acta Neuropathol 114: 97-109, 2007. PMID: 17618441. DOI: 10.1007/s00401-007-0243-4

2 Louis DN, Perry A, Reifenberger G, von Deimling A, FigarellaBranger D, Cavenee WK, Ohgaki H, Wiestler OD, Kleihues P and Ellison DW: The 2016 World Health Organization Classification of Tumors of the Central Nervous System: a summary. Acta Neuropathol 131: 803-820, 2016. PMID: 27157931. DOI: 10.1007/s00401-016-1545-1

3 Ostrom QT, Cioffi G, Gittleman H, Patil N, Waite K, Kruchko $\mathrm{C}$ and Barnholtz-Sloan JS: CBTRUS Statistical Report: Primary brain and other central nervous system tumors diagnosed in the United States in 2012-2016. Neuro Oncol 21(suppl 5): v1-v100, 2019. PMID: 31675094. DOI: $10.1093 /$ neuonc/noz150

4 Ostrom QT, Gittleman H, Liao P, Vecchione-Koval T, Wolinsky Y, Kruchko C and Barnholtz-Sloan JS: CBTRUS Statistical Report: Primary brain and other central nervous system tumors diagnosed in the United States in 2010-2014. Neuro Oncol 19(suppl 5): v1v88, 2017. PMID: 29117289. DOI: $10.1093 /$ neuonc/nox 158

5 Fang JH, Lin DD, Deng XY, Li DD, Sheng HS, Lin J, Zhang N and Yin B: Epidemiological trends, relative survival, and prognosis risk factors of WHO Grade III gliomas: A populationbased study. Cancer Med 8: 3286-3295, 2019. PMID: 31016895. DOI: $10.1002 / \mathrm{cam} 4.2164$

6 Stupp R, Brada M, van den Bent MJ, Tonn JC and Pentheroudakis G; ESMO Guidelines Working Group: Highgrade glioma: ESMO Clinical Practice Guidelines for diagnosis, treatment and follow-up. Ann Oncol 25(suppl 3): iii93-101, 2014. PMID: 24782454. DOI: 10.1093/annonc/mdu050

7 Curran WJ Jr, Scott CB, Horton J, Nelson JS, Weinstein AS, Fischbach AJ, Chang CH, Rotman M, Asbell SO, Krisch RE and Nelson DF: Recursive partitioning analysis of prognostic factors in three Radiation Therapy Oncology Group malignant glioma trials. J Natl Cancer Inst 85: 704-710, 1993. PMID: 8478956. DOI: $10.1093 /$ jnci/85.9.704

8 Forst DA, Nahed BV, Loeffler JS and Batchelor TT: Low-grade gliomas. Oncologist 19: 403-413, 2014. PMID: 24664484. DOI: 10.1634/theoncologist.2013-0345

9 Rades D, Dziggel L and Schild SE: A specific survival score for patients receiving local therapy for single brain metastasis from a gynecological malignancy. In Vivo 32: 825-828, 2018. PMID: 29936465. DOI: 10.21873 /invivo.11314
10 Rades D, Sehmisch L, Hansen HC, Dziggel L, Janssen S and Schild SE: Comparison of diagnosis-specific survival scores for patients with cerebral metastases from malignant melanoma including the new WBRT-30-MM. Anticancer Res 39: 15011505, 2019. PMID: 30842188. DOI: 10.21873/anticanres.13268

11 Rades D, Dziggel L, Manig L, Janssen S, Khoa MT, Duong VN, Khiem VH and Schild SE: Predicting survival after whole-brain irradiation for cerebral metastases in patients with cancer of the bladder. In Vivo 32: 633-636, 2018. PMID: 29695570. DOI: 10.21873/invivo. 11285

12 Rades D, Sondermann L, Motisi L, Janssen S, Cacicedo J and Schild SE: Prognostic factors and a survival score in patients irradiated for metastatic epidural spinal cord compression from urothelial carcinoma of the bladder. Anticancer Res 38: 68416846, 2018. PMID: 30504399 DOI: 10.21873/anticanres.13058

13 Park CK, Lee SH, Han JH, Kim CY, Kim DW, Paek SH, Kim DG, Heo DS, Kim IH and Jung HW: Recursive partitioning analysis of prognostic factors in WHO grade III glioma patients treated with radiotherapy or radiotherapy plus chemotherapy. BMC Cancer 9: 450, 2009. PMID: 20017960. DOI: 10.1186/ 1471-2407-9-450

14 Mayer A, Schwanbeck C, Sommer C, Stockinger M, Giese A, Renovanz M, Vaupel $\mathrm{P}$ and Schmidberger $\mathrm{H}$ : Adjuvant temozolomide-based chemoradiotherapy versus radiotherapy alone in patients with WHO III astrocytoma: The Mainz experience. Strahlenther Onkol 191: 665-671, 2015. PMID: 26025143. DOI: 10.1007/s00066-015-0855-x.

15 Fujii Y, Muragaki Y, Maruyama T, Nitta M, Saito T, Ikuta S, Iseki $\mathrm{H}$, Hongo $\mathrm{K}$ and Kawamata T: Threshold of the extent of resection for WHO Grade III gliomas: retrospective volumetric analysis of 122 cases using intraoperative MRI. J Neurosurg 129: 1-9, 2018. PMID: 28885120. DOI: 10.3171/2017.3.JNS162383

16 Witteler J, Kjaer TW, Tvilsted S, Schild SE and Rades D: Seizures prior to radiotherapy of gliomas: Prevalence, risk factors and survival prognosis. Anticancer Res 40: 3961-3965, 2020. PMID: 32620638. DOI: 10.21873/anticanres. 14388

17 Dietterle J, Wende T, Wilhelmy F, Eisenlöffel C, Jähne K, Taubenheim S, Arlt F and Meixensberger J: The prognostic value of peri-operative neurological performance in glioblastoma patients. Acta Neurochir (Wien) 162: 417-425, 2020. PMID: 31736002. DOI: 10.1007/s00701-019-04136-4
Received August 19, 2020

Revised September 6, 2020

Accepted September 7, 2020 